\title{
DIFERENCIAÇÕES ENTRE A CONTABILIDADE \\ FINANCEIRA E A CONTABILIDADE GERENCIAL: UMA PESQUISA EMPÍRICA A PARTIR DE PESQUISADORES DE VÁRIOS PAÍSES ${ }^{1,2}$ e 3
}

\section{DIFFERENCES BETWEEN FINANCIAL AND MANAGEMENT ACCOUNTING: AN EMPIRICAL RESEARCH BASED ON THE WORK OF RESEARCHERS FROM SEVERAL COUNTRIES}

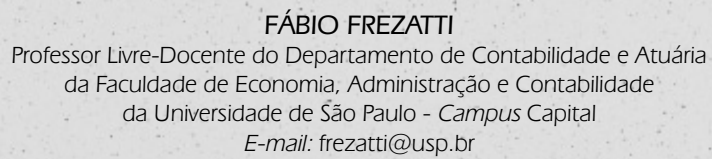

FÁBIO FREZATTI

Professor Livre-Docente do Departamento de Contabilidade e Atuária da Faculdade de Economia, Administração e Contabilidade da Universidade de São Paulo - Campus Capital E-mail:frezatti@usp.br

\author{
ANDSON BRAGA DE AGUIAR \\ Doutorando em Controladoria e Contabilidade pelo \\ Departamento de Contabilidade e Atuária \\ da Faculdade de Economia, Administração e Contabilidade \\ da Universidade de São Paulo - Campus Capital \\ E-mail: andsonbraga@yahoo.com.br
}

\section{REINALDO GUERREIRO \\ Professor Titular do Departamento de Contabilidade e Atuária \\ da Faculdade de Economia, Administração e Contabilidade da Universidade de São Paulo - Campus Capital \\ E-mail: reiguerr@uisp.br}

\section{RESUMO}

Este trabalho objetiva identificar os principais elementos que diferenciam a Contabilidade Financeira da Contabilidade Gerencial em vários países do mundo. A evolução mostra que, em algum momento, na verdade, em alguma situação essés dois ramos da Contabilidade poderiam ser assemelhados e, até mesmo, iguais. Contudo, as diferentes demandas e percepções de seus usuários, em vários países, fazem com que elas se distanciem. Para entender essas diferenças foi feita uma pesquisa em 24 países a fim de identificar os elementos que podem apresentar diferenciações entre os dois ramos da Contabilidade. Os elementos incluídos neste estudo foram definidos a partir da combinação de abordagem de vários autores. A pesquisa de campo foi desenvolvida por meio da aplicação de um questionário com estrutura de perguntas baseada em escala Likert, respondido por especialistas. Percebeu-se que os principais elementos que diferenciam as duas Contabilidades são: aplicação de princípios, foco de análise, grau de confiabilidade, agentes que influenciam ou podem influenciar, freqüência de emissão de relatórios e exigência legal de pessoal habilitado em amplitudes variadas. As diferenças reforçam a necessidade de um sistema de informação contábil que possa atender, igualmente, aos seus dois principais grupos de usuários: externos e internos.

Palavras-chave: Contabilidade Financeira; Contabilidade Gerencial; Contabilidade de Gestão.

\section{ABSTRACT}

This study aims to identifying the main elements that distinguish management accounting from financial accounting in different countries around the world. Evolution shows that, actually, at some time and in some situations, these two accounting branches could be similar and even equal. However, the different demands and perceptions of their users in different countries lead to a distance between them. To understand these differences, a study was carried out in 24 countries, in order to identify what elements can present differentiations between these two branches of accounting. The elements included in this study were defined by using a combination among different authors' approaches. The field research was developed by applying a structured questionnaire, based on a Likert scale, which was answered by specialists. The main distinctive elements of these two accounting branches are: application of standards, analytic focus, reliability level, agents which influence or can exert influence, frequency of report publication and legal requirements for trained personnel to different extents. These differences strengthen the need for an accounting information system that can equally attend to its two main user groups - internal and external.

\section{Keywords: Management Accounting; Financial Management, Managerial Accounting.}




\section{INTRODUÇÃO}

O que teria surgido primeiro? A Contabilidade para o usuário externo, aquela que apresenta informações para os agentes que estão fora da entidade? Ou seria a Contabilidade para o gestor interno da entidade, aquela que proporciona apoio ao processo decisório interno? Para Anderson et al. (1989), por exemplo, a Contabilidade Gerencial é uma extensão da Contabilidade Financeira. Kaplan e Atkinson (1989), no entanto, consideram que, em função das diferentes necessidades, a Contabilidade Financeira e a Contabilidade Gerencial necessitam tomar rumos diferentes. Existem argumentos para se aceitar ou não uma e outra forma de perceber o tema, sendo possível encontrar aqueles que pensam que a Contabilidade ainda possa ser uma única.

Richardson (2002) considera que, historicamente, existe uma dominação da Contabilidade Financeira em relação à Contabilidade Gerencial, que se constitui em relação de poder. Toms (2005) explica o desenvolvimento e convívio das duas Contabilidades na dimensão ideológica em que o fortalecimento do capital reforçou a visão do accountability interno, o que influenciou o desenvolvimento da Contabilidade Gerencial; por sua vez, a visão sociabilizante do capital, ao menos no mundo anglo-saxão, demandou a transparência das informações para o público externo à entidade, ingrediente vital ao desenvolvimento da Contabilidade Financeira.

$\mathrm{Na}$ verdade, a separação nos dois grupos decorre do entendimento de que os usuários são diferentes, que apresentam distinções significativas em suas necessidades, perspectivas e expectativas de utilização das informações contábeis. Ambos os grupos pretendem utilizar a Contabilidade como fonte básica no processo decisório, mas, não necessariamente, da mesma forma. Uma das maneiras de se diferenciar os dois grupos de usuários é olhar a "porta" da organização: da porta para dentro existem os usuários internos e da porta para fora os usuários externos. Os olhares são diferentes. Na Contabilidade para usuários externos, também denominada de Contabilidade Financeira, existem vários usuários, tais como os acionistas controladores, os gestores de fundos, os órgãos que representam o governo, os credores etc. A Contabilidade Gerencial, também, tem diferentes usuários dentro dos níveis hierárquicos ou mesmo por área funcional ou de atividade e cada um apresenta diferentes demandas. Contudo, os usuários internos, dentro de cada uma das Contabilidades, têm algo em comum: o acesso às informações em maior profundidade do que o usuário externo. Nesse sentido, a assimetria externa tende a ser maior do que a assimetria interna. É esse um dos principais motivos para que sejam agrupadas dessa maneira.

Encontram-se algumas discussões acadêmicas no sentido de questionar se existe algum país que possa (e queira) dispor de uma única Contabilidade. A dimensão país pode parecer grande para que uma generalização seja feita a respeito desse tema, mas observam-se diferentes comportamentos quando são analisados os vários países, isso significa que o entendimento a respeito desse tema parece estar longe de um consenso entre os diferentes países ou até dentro de um mesmo país. Na verdade, para que o consenso ocorra, é necessário que a conceituação do que seja Contabilidade Financeira e do que seja Contabilidade Gerencial esteja bem explicitada, pois algum distanciamento sempre poderá ser verificado e a relevância desse distanciamento pode ser variada no processo decisório das entidades.

De maneira bem simplificada, pode-se dizer que ambas as Contabilidades vivem momentos distintos. Depois dos casos Enron, Trecom, Vivendi, a Contabilidade Financeira passou por uma enorme crise, em decorrência dos questionamentos sobre o seu potencial de respostas às demandas dos agentes. A Contabilidade Gerencial, por sua vez, não se sente afetada ou pressionada por esses eventos, mas sim por outros drivers de negócios, tais como a pressão para respostas mais ágeis e claras e a contestação da utilidade de artefatos e novas respostas a demandas da gestão.

A partir dessa discussão, a questão que orienta esta pesquisa exploratória é: qual é a aderência aos elementos que diferenciam a Contabilidade Financeira da Contabilidade Gerencial em vários países? Alguns comentários se fazem necessários para tornar o desenvolvimento desta pesquisa estruturado:

\section{- Aderência}

Uma vez estabelecida a abordagem conceitual, a pesquisa pretende identificar quão coincidente a realidade de cada país se apresenta em relação à abordagem conceitual. Quanto mais evidência empírica for encontrada em cada país e no seu conjunto, maior a aderência conceitual.

\section{- Elemento}

Neste trabalho, existe a pretensão de identificar aquilo que estrutura as duas Contabilidades e que pode ser tratado, definido e utilizado de maneira distinta. A definição dos elementos foi obtida por meio de pesquisa bibliográfica apresentada no Quadro 3.

\section{- Conceito de diferença}

Diferenciação é entendida como a utilização predominante de determinados elementos por parte de uma das Contabilidades em relação à outra, e, em muitos trabalhos, não está relacionada com diferenças quantitativas, mas sim qualitativas, comportamentais, sendo tratada em detalhe em tópico específico.

\section{- Conceito de Contabilidade Financeira}

É parte do sistema que provê informações para usuários externos e é orientada pelos princípios geralmente aceitos de Contabilidade (HANSEN e MOWEN, 1997). Mesmo para os especialistas, esse tema não é percebido, pois existem componentes por eles considerados como não específicos, ou seja, não seriam unicamente aplicados à Contabilidade para o usuário externo. Hansen e Mowen (op. cit.) consideram que a Contabilidade de Custos é 
híbrida, já que é requerida de maneira significativa tanto pela Contabilidade Financeira como pela Gerencial. Para efeitos deste trabalho, ela será tratada como parte da Contabilidade Gerencial.

\section{- Conceito de Contabilidade Gerencial}

Constitui-se na parte do sistema contábil que se dedica às informações para os usuários internos da entidade (HANSEN e MOWEN, 1997). O Quadro 2 detalha alguns dos seus objetivos mais significativos. A Contabilidade Gerencial tenta, ao mesmo tempo, ser abrangente e concisa, ajustando-se constantemente para se adaptar às mudanças tecnológicas, mudanças nas necessidades dos gestores e novas abordagens das outras áreas funcionais dos negócios (LOUDERBACK et al., 2000). Também é aplicável às organizações que não objetivam o lucro porque elas precisam, assim como as demais, gerenciar o uso dos recursos de maneira otimizante para atingir seus objetivos. Louderback et al. (op. cit.) mencionam que, tanto a Contabilidade Gerencial como a Contabilidade Financeira têm em comum o fato de tratarem eventos econômicos, necessidade de quantificação de atividades econômicas e as dificuldades de obter tais informações.

- Vários países

A ambição de tratar este assunto, buscando entender o que ocorre no mundo, decorre do interesse em perceber se as diferenças podem ser explicadas por motivos que permitam aperfeiçoar a Contabilidade o que, por sua vez, colide com a praticidade e a exeqüibilidade do projeto, tornando desafiador o seu desenvolvimento. A pesquisa, no entanto, está resumida à quantidade de países em que foi possível identificar respondente interessado em participar. Este trabalho se propõe a desenvolver uma pesquisa de campo, buscando identificar os principais elementos que diferenciam as duas Contabilidades em vários países, através do entendimento de um grupo de especialistas. Dentro desse raciocínio, o respondente adequado, o especialista, é o estudioso da área, independentemente de ser possível encontrar entidades em que aquilo que deveria ocorrer não é a perspectiva encontrada ou entendida pelo especialista. Desse modo, a visão apresentada de cada país quanto aos principais elementos que diferenciam as duas Contabilidades é aquela percebida pelo especialista.

O artigo está estruturado em sete partes, incluindo essa introdução. As três partes seguintes correspondem ao referencial teórico que fundamenta este estudo. A quinta parte apresenta os aspectos metodológicos da pesquisa de campo. Em seguida, têm-se a análise de dados e as considerações finais desta pesquisa.

\section{ABORDAGENS CONCEITUAIS SOBRE A CONTABILIDADE FINANCEIRA}

As principais referências conceituais em termos de definição dos objetivos da Contabilidade Financeira provêm dos órgãos reguladores, em especial, International Accounting Standard Board (IASB), em nível mundial, Financial Accounting Standard Board (FASB), no ambiente norte-americano, e Comissão de Valores Mobiliários (CVM), quando se trata do Brasil. O Quadro $1 \boldsymbol{\nabla}$ apresenta os objetivos da Contabilidade Financeira segundo cada um desses três órgãos.

Percebe-se que, de maneira geral, o objetivo da Contabilidade Financeira se confunde com o objetivo das demonstrações contábeis que, para fins de publicação externa, precisam atender aos princípios e normas de Contabilidade Financeira.

\begin{tabular}{|c|c|}
\hline Fontes & Conceito/objetivo sobre Contabilidade Financeira \\
\hline IASB (1989) & $\begin{array}{l}\text { O objetivo das demonstrações contábeis é dar informações sobre a posição financeira, os resultados e as mudanças na } \\
\text { posição financeira de uma empresa que sejam úteis a um grande número de usuários em suas tomadas de decisão. }\end{array}$ \\
\hline FASB (1980) & $\begin{array}{l}\text { A divulgação financeira deve fornecer informações que sejam úteis para investidores e credores atuais e em potencial, } \\
\text { bem como para outros usuários que visem à tomada racional de decisões de investimento, crédito e outras semelhantes. }\end{array}$ \\
\hline CVM (1986) & $\begin{array}{l}\text { Permitir, a cada grupo principal de usuários, a avaliação da situação econômica e financeira da entidade, num sentido } \\
\text { estático, bem como fazer inferências sobre suas tendências futuras. Para a consecução desse objetivo, é preciso que } \\
\text { as empresas dêem ênfase à evidenciação de todas as informações que permitam não só a avaliação da sua situação } \\
\text { patrimonial e das mutações desse patrimônio, mas, além disso, que possibilitem a realização de inferências sobre o } \\
\text { seu futuro. }\end{array}$ \\
\hline
\end{tabular}




\section{ABORDAGENS CONCEITUAIS SOBRE A CONTABILIDADE GERENCIAL}

No que se refere à Contabilidade Gerencial, algumas referências conceituais podem ser consideradas no estudo do tema e foram sintetizadas no Quadro $2 \mathbf{0}$.

Os principais pontos em comum em termos de conceitos/objetivos da Contabilidade Gerencial são:

\section{- Composição do processo}

As etapas de composição do processo que envolvem a Contabilidade Gerencial são assemelhadas, algumas mais abrangentes e detalhadas, mas incluindo identificação, mensuração, acumulação, análise, preparação, interpretação e comunicação das informações.

- Informações para usuários

De um modo genérico e abrangente, a Contabilidade Gerencial produz informações que se destinam aos usuários internos. Especificamente, as informações são direcionadas aos gestores responsáveis pelo processo decisório.

- Apoio ao processo decisório

A descrição das etapas do processo (planejar, avaliar e controlar) convive com termos mais genéricos (dar apoio às necessidades dos gestores ou informações úteis, ou que auxiliem os gestores a atingir objetivos organizacionais).

- Conexão com os objetivos da entidade De maneira explícita, pode ser descrita como: [...] auxiliam os gestores a atingir objetivos organizacionais. (HORNGREN et al., 2004, p.4).

\begin{tabular}{|l|l|}
\hline \multicolumn{1}{|c|}{ Fontes } & \multicolumn{1}{|c|}{ Conceito/objetivo sobre Contabilidade Gerencial } \\
\hline $\begin{array}{l}\text { Anderson, Needles e } \\
\text { Cadwell (1989) }\end{array}$ & $\begin{array}{l}\text { Processo de identificação, mensuração, acumulação, análise, preparação, interpretação e comunicação } \\
\text { da informação financeira usada pelos gestores para planejamento, avaliação e controle. A informação } \\
\text { financeira possibilita aos gestores, de um lado, o uso apropriado de recursos, de outro lado, a prestação } \\
\text { de contas (accountability) decorrente desse uso. }\end{array}$ \\
\hline Louderback et al. (2000) & Prover informações para dar apoio às necessidades dos gestores internos da organização. \\
\hline Anthony e Welsch (1981) & Fornecer informações úteis para os gestores, que são pessoas que estão dentro da organização. \\
\hline Hansen e Mowen (1997) & $\begin{array}{l}\text { Identificar, coletar, mensurar, classificar, e reportar informações que são úteis para os gestores no planeja- } \\
\text { mento, controle e processo decisório. }\end{array}$ \\
\hline $\begin{array}{l}\text { Horngren, Foster e Datar } \\
\text { (2000) }\end{array}$ & $\begin{array}{l}\text { Medir e reportar as informações financeiras e não-financeiras que ajudam os gestores a tomar decisões, } \\
\text { para atingir os objetivos da organização. }\end{array}$ \\
\hline $\begin{array}{l}\text { Horngren, Sundem e } \\
\text { Stratton (2004) }\end{array}$ & $\begin{array}{l}\text { Processo de identificar, mensurar, acumular, analisar, preparar, interpretar e comunicar informações que } \\
\text { auxiliem os gestores a atingir objetivos organizacionais. }\end{array}$ \\
\hline
\end{tabular}

Quadro 2 Comparação de conceituações disponíveis

\section{PRINCIPAIS DIFERENCAS ENTRE A CONTABILIDADE FINANCEIRA E A CONTABILIDADE GERENCIAL}

Apresentam-se, no Quadro $3 \boldsymbol{\bullet}$, algumas diferenciações entre as Contabilidades Financeira e Gerencial descritas por vários autores.

Os aspectos de diferenciação serão considerados na elaboração das questões para identificar as peculiaridades de cada uma das Contabilidades. Como seria de esperar, cada autor aborda o tema de maneira peculiar. O primeiro esforço na pesquisa consiste em aglutinar as abordagens, a partir da congruência de elementos que correspondam aos pontos de análise da pesquisa. De maneira geral, as diferenças mais enfatizadas foram:

- Usuários primários das informações: ressaltados por Anderson, Needles e Cadwell (1989), Louderback et al. (2000) e Horngren, Sundem e Stratton (2004)

No caso da Contabilidade Financeira, trata-se das pessoas e entidades externas à entidade, enquanto, na Contabilidade Gerencial, são os vários níveis hierárquicos e mesmo as áreas funcionais internas que se constituem nos usuários.

- Tipos de sistemas contábeis: ressaltados por Anderson, Needles e Cadwell (1989), Louderback et al. (2000) e Anthony e Welsch (1981)

No caso da Contabilidade Financeira, a abordagem das partidas dobradas é compulsória, enquanto, na Contabilidade Gerencial, podem existir ajustes mesmo sem contrapartida. Nessa última, podem ser utilizados sistemas de informações distintos daquele usado na Contabilidade Financeira e mesmo informações não-monetárias.

- Liberdade de escolha: ressaltada por Anderson, Needles e Cadwell (1989), Anthony e Welsch (1981), Hansen e Mowen (1997), Horngren, Foster e Datar (2000) e Horngren, Sundem e Stratton (2004) A Contabilidade Financeira tem como característica a aderência compulsória a princípios contábeis do 


\begin{tabular}{|c|c|}
\hline Fontes & Elementos de diferenciação entre a Contabilidade Financeira e Gerencial \\
\hline Anderson, Needles e Cadwell (1989) & $\begin{array}{l}\text { 1) Usuários primários da informação. } \\
\text { 2) Tipos de sistemas contábeis. } \\
\text { 3) Restrições de definições. } \\
\text { 4) Unidades de mensuração. } \\
\text { 5) Foco da análise. } \\
\text { 6) Freqüência de relatórios. } \\
\text { 7) Grau de confiabilidade da informação gerada. }\end{array}$ \\
\hline Louderback et al. (2000) & $\begin{array}{l}\text { 1) Diferentes audiências (interna e externa à empresa). } \\
\text { 2) Foco de classificação (controlabilidade, comportamento e responsabilidade no caso da } \\
\text { Contabilidade Gerencial). } \\
\text { 3) Fontes das informações (no caso da gerencial, não apenas financeiras). } \\
\text { 4) Usuário específico versus usuário generalizado. } \\
\text { 5) Foco nas informações passadas e foco nas informações que permitam entender, planejar } \\
\text { e prever o futuro. }\end{array}$ \\
\hline Anthony e Welsch (1981) & $\begin{array}{l}\text { 1) Estrutura: a Contabilidade Financeira. } \\
\text { 2) Princípios: GAAP versus os três princípios. } \\
\text { 3) Inclui informações não-monetárias. } \\
\text { 4) Diferentes enfoques temporais: passado e futuro. } \\
\text { 5) Freqüência de relatórios. } \\
\text { 6) Diferentes enfoques na precisão. } \\
\text { 7) Fim em si mesmo ou não. }\end{array}$ \\
\hline Hansen e Mowen (1997) & 1) Regras específicas versus gerais. \\
\hline Horngren, Foster e Datar (2000) & $\begin{array}{l}\text { 1) Princípios norteadores. } \\
\text { 2) Diferentes ênfases no futuro e no passado. } \\
\text { 3) Diferentes interesses sobre o comportamento. }\end{array}$ \\
\hline Horngren, Sundem e Stratton (2004) & $\begin{array}{l}\text { 1) Usuários primários. } \\
\text { 2) Liberdade de escolha. } \\
\text { 3) Implicações comportamentais. } \\
\text { 4) Enfoque de tempo. } \\
\text { 5) Horizonte de tempo. } \\
\text { 6) Relatórios. } \\
\text { 7) Delineamento de atividades. }\end{array}$ \\
\hline
\end{tabular}

Quadro 3 | Principais diferenças entre a Contabilidade Financeira e a Contabilidade Gerencial

país. Por sua vez, na Contabilidade Gerencial, embora fundamental que sejam definidos para a entidade, pode até não haver critérios formalizados.

- Unidades de mensuração: ressaltadas por Anderson, Needles e Cadwell (1989) e Anthony e Welsch (1981)

Em termos de unidade de mensuração, a moeda utilizada na Contabilidade Financeira é a moeda local, do país. Por sua vez, na Contabilidade Gerencial, qualquer moeda pode ser usada e pode considerar, inclusive, unidades de mensuração não-monetárias, tais como horas de trabalho, quilos, litros etc.

- Foco de análise: ressaltado por Anderson, Needles e Cadwell (1989), Louderback et al. (2000), Anthony e Welsch (1981), Horngren, Foster e Datar (2000) e Horngren, Sundem e Stratton (2004)

Esse quesito pode ser entendido de várias maneiras. Pode levar em conta a perspectiva de detalhamen- to que os relatórios exijam ou mesmo a dimensão passada ou futura que se pretenda. Pode ter uma perspectiva comportamental distinta em relação a uma dada área ou grupo de gestores.

- Horizonte temporal e freqüência da emissão das demonstrações para os usuários: ressaltados por Anderson, Needles e Cadwell (1989), Anthony e Welsch (1981) e Horngren, Sundem e Stratton (2004)

A questão temporal pode afetar o tema tanto pelo período de cobertura de relatórios quanto a freqüência de sua emissão.

- Grau de confiabilidade: ressaltado por Anderson, Needles e Cadwell (1989) e Anthony e Welsch (1981)

A confiabilidade está ligada à objetividade e verificabilidade, materializando-se por algum tipo de auditoria na Contabilidade Financeira. Na Conta- 
bilidade Gerencial, em condições normais, dada a subjetividade de alguns números, essa possibilidade de auditoria se mostra diferente.

- Existência de órgãos reguladores ou definidores de regras: identificada pelos autores deste trabalho

Dada a sua demanda normativa, na Contabilidade Financeira, podem ser encontrados órgãos ligados ou não às autoridades governamentais, que definam ou recomendem regras e princípios para a elaboração das demonstrações. Em outros casos, essas mesmas normas são usadas pela Contabilidade Gerencial não por imposição, mas sim por conveniência.

- Exigência legal de profissional especializado: identificada pelos autores deste trabalho

Em alguns países, a responsabilidade e a autoridade para elaborar as demonstrações da Contabilidade Financeira estão limitadas a profissionais graduados em Contabilidade e registrados em seus órgãos de classe. Já na Contabilidade Gerencial, a compulsoriedade pode não ser o padrão.

\section{DESIGN DA PESQUISA DE CAMPO}

A pesquisa tem por característica ser empírico-analítica, do tipo exploratória e se propõe, como resultado, a apresentar uma visão descritiva da diferenciação das duas Contabilidades, em uma série de países, sob o ponto de vista de especialistas. Portanto, para cada país, o que se está refletindo é o modo pelo qual o especialista entende que as duas Contabilidades se diferenciam. Muito antes da precisão, este trabalho tem por objetivo despertar o interesse pelo tema e buscar respostas para questões ligadas às peculiaridades que possam ajudar a entender o desenvolvimento da Contabilidade em diferentes ambientes. $\mathrm{O}$ design na pesquisa leva em conta três aspectos:

- as informações desejadas a partir dos elementos de diferenciação;

- identificação e análise da adequação do respondente;

- metodologia para tratamento das informações.
Detalhadamente, foram consideradas:

\subsection{As informações desejadas a partir dos elementos de diferenciação}

A estruturação da pesquisa levou em conta combinação de abordagem dos vários autores, conforme apresentado no item 4. Uma vez identificados os elementos desejados, as variáveis que podem captar esses dados foram especificadas em respectivas escalas e construídas as perguntas que compõem o questionário. Excluindo-se as questões destinadas a captar respostas abertas, as escalas em que os dados serão coletados são binária e ordinal.

A pesquisa leva em conta a aplicação de um questionário para profissionais, de vários países, com questões sobre os nove blocos especificados no Quadro $4 \mathbf{0}$.

\begin{tabular}{|c|c|c|c|c|}
\hline & Descrição & Escala & Foco das questões & Bloco \\
\hline \multirow[t]{4}{*}{ 1) } & \multirow[t]{4}{*}{ Usuários básicos da informação. } & Binária & 1.1) Necessidade da existência das duas Contabilidades. & \multirow{4}{*}{1} \\
\hline & & Resposta aberta & 1.2) Razões para resposta não Binária. & \\
\hline & & Ordinal & 1.3) Razões para não. & \\
\hline & & Ordinal & 1.4) Razões para sim. & \\
\hline 2) & Tipos de sistemas contábeis. & Binária & 2.1) Base de dados ligados à Contabilidade Financeira. & 2 \\
\hline \multirow[t]{3}{*}{ 3) } & \multirow[t]{3}{*}{ Liberdade de escolha. } & Binária & 3.1) Utilização dos princípios contábeis de maneira igual. & \multirow{3}{*}{3} \\
\hline & & Binária & 3.2) Identificação de diferenças no balanço. & \\
\hline & & Binária & 3.3) Identificação de diferenças na demonstração de resultados. & \\
\hline \multirow[t]{3}{*}{ 4) } & \multirow[t]{3}{*}{ Unidades de mensuração. } & Resposta aberta & 4.1) Moeda utilizada. & \multirow{3}{*}{4} \\
\hline & & Binária & 4.2) Mesma moeda para ambas as Contabilidades. & \\
\hline & & Resposta aberta & 4.3) Razões para resposta não Binária. & \\
\hline 5) & Foco de análise. & Ordinal & 5.1) Grau de detalhamento de estruturação de dados. & 5 \\
\hline 6) & $\begin{array}{l}\text { Horizonte temporal e freqüência } \\
\text { de emissão de relatórios. }\end{array}$ & Binária & 6.1) Freqüência de emissão de relatórios. & 6 \\
\hline 7) & Grau de confiabilidade. & Binária & 7.1) Exigibilidade de algum processo de auditoria. & 7 \\
\hline \multirow[t]{2}{*}{ 8) } & \multirow{2}{*}{$\begin{array}{l}\text { Órgãos reguladores } \\
\text { ou de influência. }\end{array}$} & Ordinal & 8.1) Possibilidade de influência de órgãos ou pessoas. & \multirow{2}{*}{8} \\
\hline & & Ordinal & 8.2) Influência de órgãos ou pessoas. & \\
\hline \multirow{2}{*}{ 9) } & \multirow{2}{*}{$\begin{array}{l}\text { Responsável técnico } \\
\text { pela elaboração. }\end{array}$} & Binária & 9.1) Credenciamento como fator compulsório. & \multirow{2}{*}{9} \\
\hline & & Binária & 9.2) Graduação em Contabilidade como fator compulsório. & \\
\hline
\end{tabular}

Quadro 4 Relacionamento entre conceitos e foco das questões 


\begin{tabular}{|c|c|c|c|}
\hline País & Respondente & País & Respondente \\
\hline \multirow{3}{*}{ África do Sul } & RJJ Barnard & Grécia & George Angelakis \\
\hline & Susan Visser & Holanda & Willem van der Loos \\
\hline & J P Fouche & Índia & Bhabatosh Banerjee \\
\hline Alemanha & Franz Egle & Itália & Alberto Quagli \\
\hline Argentina & Amaro Yardin & Japão & Keuji Yasukata \\
\hline \multirow{2}{*}{ Brasil } & Luiz N. de Carvalho & México & Salvador R. de Chávez \\
\hline & Welington Rocha & Noruega & Frystein Gjesdal \\
\hline Canadá & John Parkinson & Polônia & Wojciech A. Nowak \\
\hline China & Zhang Rujiin & Portugal & José M. de Carvalho \\
\hline Colômbia & Patrícia Gonzalez & \multirow{2}{*}{ Suécia } & Christian Ax (Ger) \\
\hline Espanha & Javier Zuera & & Lars Bergtsson \\
\hline EUA & Surendra P. Agrawal & Taiwan & Anne Wu \\
\hline Finlândia & Peter Seiamala & Tunísia & Mohsen Soceissi \\
\hline Grã-Bretanha & David Otley & Uruguai & Carolina Asuaga \\
\hline
\end{tabular}

Quadro 5 Relação de países pesquisados e respondentes

\subsection{Identificação e análise da adequação do respondente}

Levando em consideração a dificuldade em desenvolver a pesquisa de campo de maneira mais capilarizada, foi decidido, pelos autores, que se levaria em conta a aplicação de um questionário para diversos especialistas de vários países. Dessa maneira, não se pretende afirmar que o trabalho represente 0 que ocorre nos países, mas sim o que alguns estudiosos acreditam que seja o perfil do país. Os respondentes de cada país foram identificados como atuantes nas suas áreas, tendo o título de doutor, podendo ser docentes e/ou consultores profissionais. Em alguns países, já se esperava que a Contabilidade Gerencial, enquanto área de conhecimento, se mostrasse definida, ao passo que em outros isso não ocorreria, o que dificulta a seleção do respondente adequado. A opção adotada foi a de identificar e reconhecer profissional academicamente qualificado em termos de titulação, independentemente de ele se classifi- car como atuante na Contabilidade Financeira, Gerencial ou ambas. No caso de respostas conflitantes ou complexidade no entendimento das respostas por parte dos autores deste estudo, outro pesquisador foi convidado a contribuir.

Foram identificados cerca de 40 países e seus respectivos respondentes. Os questionários foram enviados para o endereço eletrônico deles, tendo sido devolvidos de 24 (vinte e quatro) países apresentados no Quadro 50.

\subsection{Metodologia para tratamento das informações}

A análise dos dados obtidos por meio de aplicação de questionário com estrutura de perguntas baseada em escala Likert foi realizada por meio da descrição dos elementos incluídos neste estudo, procurando-se destacar aqueles que diferenciam a Contabilidade Financeira da Contabilidade Gerencial.

\section{ANÁLISE DOS DADOS}

A análise dos dados considerou cada elemento incluído neste estudo que poderia apresentar diferenciações entre a Contabilidade Financeira e a Contabilidade Gerencial. Será analisado inicialmente cada bloco do questionário.

\subsection{Bloco 1}

Usuários básicos da informação

O objetivo desse Bloco foi identificar a opinião dos respondentes, sobre a necessidade de dispor de duas Contabilidades, assim como os motivos que justificam a escolha. Ver Tabela 10.

Os motivos mais citados pelos respondentes que indicaram a necessidade de existência de duas Contabilidades foram: "as diferenças qualitativas são significativas" (três respondentes), "o custo-benefício compensa" (dois respondentes) e "as diferenças numéricas são significativas" (dois respondentes). Dois respondentes indicaram outras justificativas, enquanto os demais não responderam.

Por sua vez, aqueles que responderam "não" para essa questão apresentaram as seguintes alternativas: "as diferenças numéricas não são significativas" (três respondentes), "o custo-benefício não compensa" (dois respondentes) e "as diferenças qualitativas não são significativas" (um respondente). Dois respondentes indicaram outras justificativas, enquanto os demais não responderam.

Da observação das justificativas indicadas, percebe-se que não parece existir um motivo absoluto para a existência de uma ou de duas Contabilidades, mas sim uma conjugação de fatores e percepções opostas em relação aos motivos que levariam à existência das duas Contabilidades.

Por fim, três respondentes consideraram que, dependendo da origem do capital, estilo gerencial, cultura orga- 
Tabela 1 - Opinião dos respondentes sobre a necessidade de dispor de duas Contabilidades

\begin{tabular}{l|c|c}
\multicolumn{1}{c|}{$\begin{array}{c}\text { Resposta } \\
\text { Há necessidade de duas } \\
\text { Contabilidades. }\end{array}$} & $67 \%$ & $\begin{array}{l}\text { Países } \\
\text { Argentina, Colômbia, China, Japão e Uruguai. }\end{array}$ \\
\hline $\begin{array}{l}\text { Não há necessidade de } \\
\text { duas Contabilidades. }\end{array}$ & $21 \%$ & Taiwan, Holanda, Espanha, Tunísia e USA. \\
\hline Depende. & $13 \%$ & Polônia, Finlândia e Grã-Bretanha.
\end{tabular}

nizacional e outras variáveis, a necessidade da existência ou não de duas Contabilidades seria determinada.

\subsection{Bloco 2}

\section{Tipos de sistemas contábeis}

O objetivo desse Bloco foi identificar se, na opinião dos respondentes, o banco de dados contábil seria o mesmo tanto para a Contabilidade Financeira quanto para a Gerencial e se, além de dados monetários, são utilizados dados não-monetários. Ver Tabela $2 \mathbf{0}$.

Destacando-se os resultados mais representativos, percebe-se que $46 \%$ dos respondentes consideraram que não deve se utilizar a mesma base de dados para ambas as Contabilidades. Esse resultado mostra consistência com um outro item no qual $71 \%$ dos respondentes indicaram que a Contabilidade Gerencial pode utilizar outras bases de dados monetárias e que essas não têm que, necessariamente, ser consistentes com a base de dados da Contabilidade Financeira. Destaque-se, também, a indicação da possibilidade de utilização de dados não-monetários, o que permite dizer que a necessidade da Contabilidade Gerencial tratar elementos não financeiros é relativamente forte.

\subsection{Bloco 3}

\section{Liberdade de escolna}

O objetivo desse Bloco foi identificar se, na opinião dos respondentes, a Contabilidade Gerencial teria que adotar os mesmos valores decorrentes da aplicação dos princípios contábeis. Vide Tabela $3 \boldsymbol{0}$.

Analisando os princípios contábeis definidos para a Contabilidade Financeira, pode ser percebido que, para a Contabilidade Gerencial, as respostas mais representativas foram:

- Metade dos respondentes considera que, sob a perspectiva do princípio da entidade, a Contabilidade Gerencial deveria proporcionar os mesmos números que a Contabilidade Financeira. Cabe destacar que, para os respondentes que indicaram não, uma provável justificativa seria a importância dada à distinção entre a entidade jurídica e a entidade econômica.

- $67 \%$ dos respondentes consideraram que o princípio da continuidade seja igualmente utilizável para as duas Contabilidades. Destaque-se que, para aqueles respondentes que indicaram não, uma pro-

Tabela 2 Tipos de sistemas contábeis

\begin{tabular}{|c|c|c|c|}
\hline Descrição & Não & Sim & Não Respondeu \\
\hline Utiliza exclusivamente a base de dados originária da Contabilidade Financeira (double entry). & $46 \%$ & $33 \%$ & $21 \%$ \\
\hline Utiliza outra base de dados monetária que não a Contabilidade Financeira. & $29 \%$ & $29 \%$ & $42 \%$ \\
\hline $\begin{array}{l}\text { Utiliza adicionalmente outras bases de dados monetárias não necessariamente consistentes } \\
\text { com a Contabilidade Financeira. }\end{array}$ & $13 \%$ & $71 \%$ & $17 \%$ \\
\hline Utiliza base de dados não-monetários. & $21 \%$ & $50 \%$ & $29 \%$ \\
\hline $\begin{array}{l}\text { Utiliza outra base de dados monetária que não a Contabilidade Financeira, bases de dados } \\
\text { não-monetárias. }\end{array}$ & $25 \%$ & $33 \%$ & $42 \%$ \\
\hline $\begin{array}{l}\text { Utiliza outra base de dados monetária que não a Contabilidade Gerencial e bases de dados } \\
\text { não-monetárias. }\end{array}$ & $38 \%$ & $17 \%$ & $46 \%$ \\
\hline
\end{tabular}

Tabela 3 Liberdade de escolha

\begin{tabular}{l|c|c|c}
\multicolumn{1}{c|}{ Descrição } & Não & Sim & Não Respondeu \\
Entidade. & $33 \%$ & $50 \%$ & $17 \%$ \\
\hline Continuidade. & $25 \%$ & $67 \%$ & $8 \%$ \\
\hline Custo histórico como base de valor. & $58 \%$ & $25 \%$ & $17 \%$ \\
\hline Realização da receita e confronto com despesas. & $54 \%$ & $29 \%$ & $17 \%$ \\
\hline Prudência. & $54 \%$ & $29 \%$ & $17 \%$ \\
\hline
\end{tabular}


vável interpretação seria que a continuidade de uma empresa estaria sempre sendo questionada, sem garantias, o que permitiria conseqüências na forma de avaliação de ativos.

- O resultado mais representativo, em termos de questionamento, está justamente no princípio do custo histórico como base de valor. $58 \%$ dos respondentes não consideram que a Contabilidade Gerencial tem que produzir números de acordo com esse princípio. Tal fato pode ser decorrência de que esse princípio não tem o mesmo valor preditivo para os gestores de outros critérios (ex. custo corrente, valor de liquidação, valor presente do fluxo futuro de caixa etc.).

- O princípio da realização da receita, também, apresenta um alto nível de discordância. 54\% dos respondentes, igualmente, consideram que a Contabilidade Gerencial não tem que mensurar o valor da receita apenas pelo princípio da competência. Uma provável justificativa para esse entendimento seria que esse princípio não resolve problemas internos à entidade no que se refere à apropriação de receitas, exigindo uma abordagem gerencial diferente daquela imposta pelo fisco e pela legislação societária.

- O princípio da prudência, também, apresenta o mesmo nível de questionamento do princípio anterior. 54\% dos respondentes consideram que a aplicação desse princípio na Contabilidade Gerencial deve proporcionar diferentes números nos resultados das empresas. Considerando as respostas para as questões referentes ao balanço patrimonial e demonstração de resultados, percebe-se que exis- te uma associação com a gestão da provisão para devedores duvidosos e estoques, contas que a Contabilidade Gerencial se propõe a customizar atendendo à necessidade informacional, diferentemente da Contabilidade Financeira, afetada por agentes externos.

\subsection{Bloco 4}

Unidades de mensuração

O objetivo desse Bloco foi identificar qual(is) a(s) moeda(s) de publicação das demonstrações contábeis, em especial o balanço patrimonial e a demonstração do resultado do exercício. Além disso, se para as demonstrações provenientes da Contabilidade Gerencial seria(m) utilizada(s) a(s) mesma(s) moeda(s). Ver Tabela $4 \boldsymbol{0}$

A maior parte dos respondentes (75\%) considera que as demonstrações da Contabilidade Financeira são apresentadas apenas na moeda local. Quando perguntado se as demonstrações da Contabilidade Gerencial são divulgadas apenas na moeda local, 63\% disseram que sim, enquanto $21 \%$ responderam que as informações da Contabilidade Gerencial são divulgadas em mais de uma moeda e, claramente, estão pensando em empresas multinacionais.

\subsection{Bloco 5 Foco de análise}

O objetivo desse Bloco é identificar qual o foco de análise tanto da Contabilidade Financeira quanto da Contabilidade Gerencial. Ver Tabela $5 \mathbf{0}$.

Como resultados mais representativos, destacam-se:

- A análise da empresa como um todo é relevante para as duas Contabilidades: $46 \%$ para a Contabilidade Financeira e 58\% para a Contabilidade Geren-

Tabela 4 Unidades de mensuração

\begin{tabular}{l|c}
\multicolumn{1}{c|}{ Moeda } & $\%$ \\
\hline Não respondeu. & $17 \%$ \\
\hline Moeda local. & $75 \%$ \\
\hline Moeda local e Dólar. & $4 \%$ \\
\hline Moeda local, Euro e Dólar. & $4 \%$
\end{tabular}

Tabela 5 - Foco de análise

\begin{tabular}{|c|c|c|c|c|c|c|}
\hline \multirow[t]{2}{*}{ Descrição } & \multicolumn{3}{|c|}{ Contabilidade Financeira } & \multicolumn{3}{|c|}{ Contabilidade Gerencial } \\
\hline & Não & Sim & Não Respondeu & Não & Sim & Não Respondeu \\
\hline As informações valorizam mais a empresa como um todo. & $42 \%$ & $46 \%$ & $13 \%$ & $25 \%$ & $58 \%$ & $17 \%$ \\
\hline As unidades de negócios são valorizadas na análise. & $58 \%$ & $25 \%$ & $17 \%$ & $8 \%$ & $83 \%$ & $8 \%$ \\
\hline Os centros de custos são valorizados na análise. & $71 \%$ & $4 \%$ & $25 \%$ & $4 \%$ & $92 \%$ & $4 \%$ \\
\hline As análises por grupos de produtos são valorizadas na análise. & $75 \%$ & $4 \%$ & $21 \%$ & $8 \%$ & $88 \%$ & $4 \%$ \\
\hline As análises por projetos são valorizadas na análise. & $67 \%$ & $13 \%$ & $21 \%$ & $13 \%$ & $71 \%$ & $17 \%$ \\
\hline $\begin{array}{l}\text { O plano de contas das demonstrações financeiras é único } \\
\text { para ambas as Contabilidades. }\end{array}$ & $38 \%$ & $46 \%$ & $17 \%$ & $50 \%$ & $33 \%$ & $17 \%$ \\
\hline $\begin{array}{l}\text { Os critérios para detalhamento de uma área ou conta leva } \\
\text { em consideração razões comportamentais. }\end{array}$ & $71 \%$ & $17 \%$ & $13 \%$ & $29 \%$ & $58 \%$ & $13 \%$ \\
\hline
\end{tabular}


cial. Essa percepção traz subsídio sobre a discussão do foco no todo e nas partes da entidade.

- Percebe-se que apenas $25 \%, 4 \%, 4 \%$ e $13 \%$ dos respondentes consideram que a análise por unidade de negócios, por centro de custos, por grupo de produtos e por projetos, respectivamente, é valorizada pela Contabilidade Financeira. Essas são análises direcionadas, principalmente, para usuários internos. Provavelmente, isso se deve ao gerenciamento das informações evitando que a concorrência se beneficie delas, constituindo-se na "proteção assimétrica".

- Por outro lado, a Contabilidade Gerencial valoriza significativamente a análise por unidade de negócios $(83 \%)$, por centro de custos $(92 \%)$, por grupo de produtos $(88 \%)$ e por projetos $(71 \%)$, o que realmente é consistente quando se considera que essas análises são direcionadas para os usuários internos.

- Percebe-se uma tendência em considerar que o plano de contas adotado pela Contabilidade Financeira não seja o mesmo para a Contabilidade Gerencial.

- A presença de questões comportamentais na definição de uma área e do plano de contas é pouco apoiada na Contabilidade Financeira (17\%), enquanto na Contabilidade Gerencial parece ter relevância (58\%).

\subsection{Bloco 6 \\ Horizonte temporal e freqüência de emissão de relatórios}

A sessão de perguntas sobre o horizonte temporal e a freqüência de emissão dos relatórios contábeis, principalmente balanço patrimonial e demonstração de resultados, diz respeito ao período mais freqüente e sua adequação, segundo a opinião dos respondentes. A periodicidade mensal não elimina completamente a possibilidade de também ser encontrada a periodicidade semestral, mas mostra o foco de prioridade predominante do grupo de respondentes. Ver Tabela 60.

Destaquem-se como respostas mais significativas:

- No que se refere à Contabilidade Financeira, percebe-se que publicações semanais não são indicadas por nenhum respondente. Publicações trimestrais e semestrais também apresentam aderência de apenas $17 \%$ dos respondentes, em ambos os casos.
Publicação mensal é considerada uma periodicidade adequada para $25 \%$ dos respondentes. O foco da publicação dos relatórios financeiros parece estar na periodicidade anual, embora, curiosamente, exista uma equivalência entre os que consideram essa periodicidade adequada e os que pensam o contrário. Parece não haver uma posição definida por parte dos respondentes a respeito de uma periodicidade adequada para os relatórios financeiros, embora a periodicidade anual se apresente como a mais indicada.

- Quanto à Contabilidade Gerencial, pode-se inferir que os respondentes não consideram adequada uma publicação semanal, trimestral, semestral e anual, sendo a periodicidade mensal a mais adequada na opinião de $67 \%$ dos respondentes. Esse aspecto indica que, embora existam estudos destacando a importância de relatórios gerenciais com uma periodicidade inferior a um mês, não há ainda um consenso nesse sentido, o que pode refletir que essa periodicidade inferior a um mês não seria capaz de trazer informações relevantes a ponto de o usuário conseguir utilizá-las no processo decisório. Quanto às periodicidades superiores à mensal, parece que, na opinião dos respondentes, não seriam necessárias essas publicações com outra periodicidade dada a publicação mensal.

\subsection{Bloco 7}

\section{Grau de confiabilidade}

Esse Bloco tem o objetivo de identificar se, na opinião dos respondentes, é obrigatória a auditoria das informações financeiras e/ou gerenciais. Vide Tabela $7 \boldsymbol{Q}$.

As respostas mais representativas são discutidas a seguir:

- Para a Contabilidade Financeira, percebe-se que a auditoria interna é de pouca relevância. No entanto, todas as respostas válidas indicam que a auditoria externa dos relatórios financeiros é essencial. Como conseqüência, mais da metade dos respondentes não considera que a auditoria possa ser opcional para os relatórios financeiros. Os resultados obtidos apresentam consistência com o histórico de surgimento da auditoria externa.

- Para a Contabilidade Gerencial, os resultados são praticamente opostos. A auditoria interna também

Tabela 6 Horizonte temporal e freqüência de emissão de relatórios contábeis

\begin{tabular}{l|c|c|c|c|c|c}
\multirow{2}{*}{ Descrição } & \multicolumn{3}{|c|}{ Contabilidade Financeira } & \multicolumn{3}{c}{ Contabilidade Gerencial } \\
\cline { 2 - 7 } & Não & Sim & Não respondeu & Não & Sim & Não respondeu \\
\hline Semanal & $92 \%$ & 0 & $8 \%$ & $75 \%$ & $17 \%$ & $8 \%$ \\
\hline Mensal & $67 \%$ & $25 \%$ & $8 \%$ & $25 \%$ & $67 \%$ & $8 \%$ \\
\hline Trimestral & $75 \%$ & $17 \%$ & $8 \%$ & $83 \%$ & $8 \%$ & $8 \%$ \\
\hline Semestral & $75 \%$ & $17 \%$ & $8 \%$ & $83 \%$ & $8 \%$ & $8 \%$ \\
\hline Anual & $46 \%$ & $46 \%$ & $8 \%$ & $79 \%$ & $13 \%$ & $8 \%$
\end{tabular}


Tabela 7 || Grau de confiabilidade

\begin{tabular}{l|c|c|c|c|c|c}
\multirow{2}{*}{ Descrição } & \multicolumn{3}{|c|}{ Contabilidade Financeira } & \multicolumn{3}{c}{ Contabilidade Gerencial } \\
\cline { 2 - 7 } & Não & Sim & Não Respondeu & Não & Sim & Não Respondeu \\
\hline Auditoria interna da empresa. & $17 \%$ & $29 \%$ & $54 \%$ & $25 \%$ & $21 \%$ & $54 \%$ \\
\hline Auditoria externa à empresa. & 0 & $92 \%$ & $8 \%$ & $83 \%$ & $4 \%$ & $13 \%$ \\
\hline Não exigem auditoria. & $58 \%$ & 0 & $42 \%$ & 0 & $58 \%$ & $42 \%$
\end{tabular}

parece de pouca relevância aqui. No entanto, a maioria considera que a auditoria externa não é necessária para os relatórios gerenciais. Um respondente indicou que os relatórios gerenciais precisam passar por auditoria externa. Percebe-se também que mais da metade não considera ser necessária a auditoria para os relatórios gerenciais. Os resultados obtidos também são consistentes quando se considera que os relatórios gerenciais são destinados principalmente para gestores, não apresentando as mesmas características que tornam necessária a auditoria externa para os relatórios financeiros.

\subsection{Bloco 8}

Órgãos reguladores ou de influência

Esse Bloco tem dois objetivos inter-relacionados. O primeiro é identificar, na opinião dos respondentes, que agentes poderiam influenciar ou regular a elaboração tanto de relatórios financeiros quanto gerenciais. $O$ segundo objetivo é identificar, na opinião dos respondentes, quais agentes estão efetivamente influenciando ou regulando ambas as Contabilidades. Ver Tabela 80

Os resultados mais representativos são destacados a seguir:

- Para a Contabilidade Financeira, percebe-se que os acionistas controladores são os que aparecem como menos prováveis de exercer influência sobre os relatórios financeiros. Outras empresas do mercado, órgãos de classe, órgão fiscal de seu país e gestores também apresentam pequena possibi- lidade de influenciar os relatórios financeiros. Por outro lado, os órgãos governamentais, o FASB local (que, no caso do Brasil, seria a Comissão de Valores Mobiliários) e a legislação societária têm possibilidade de exercer forte influência e poder regulatório sobre os relatórios financeiros. Também pode influenciar ou regular a publicação de relatórios financeiros, o órgão fiscal de seu país que, no caso brasileiro, seria a Secretaria da Receita Federal. Interessante notar o caso de órgãos reguladores de outros países, cujo posicionamento dos respondentes não indica qualquer tendência. Pode-se concluir que são os órgãos normativos que podem determinar as práticas de Contabilidade Financeira adotadas pelas empresas.

- Para a Contabilidade Financeira, percebe-se que, com exceção de "outras empresas do mercado" e "os gestores", os demais agentes têm pequena possibilidade de exercer influência ou regular os relatórios gerenciais. Os gestores aparecem como os prováveis de exercerem forte influência sobre os relatórios gerenciais, enquanto outras empresas do mercado também aparecem com possibilidade representativa de exercer essa influência. Nesse sentido, pode-se considerar que a elaboração dos relatórios gerenciais poderá depender, primeiramente, do estilo gerencial do gestor e, em segundo lugar, de aspectos miméticos, ou seja, das práticas de Contabilidade Gerencial que têm sido bem-sucedidas em outras empresas.

Tabela 8 - Agentes que poderiam influenciar ou regular os relatórios financeiros e gerenciais

\begin{tabular}{|c|c|c|c|c|c|c|}
\hline \multirow{2}{*}{ Descrição } & \multicolumn{3}{|c|}{ Contabilidade Financeira } & \multicolumn{3}{|c|}{ Contabilidade Gerencial } \\
\hline & Não & Sim & Não Respondeu & Não & Sim & Não Respondeu \\
\hline Outras empresas do mercado. & $33 \%$ & $17 \%$ & $50 \%$ & $17 \%$ & $50 \%$ & $33 \%$ \\
\hline Órgãos de classe. & $25 \%$ & $25 \%$ & $50 \%$ & $38 \%$ & $25 \%$ & $38 \%$ \\
\hline O FASB local. & $4 \%$ & $79 \%$ & $17 \%$ & $38 \%$ & $17 \%$ & $46 \%$ \\
\hline $\begin{array}{l}\text { Órgãos governamentais } \\
\text { (federal, estadual ou municipal). }\end{array}$ & $4 \%$ & $83 \%$ & $13 \%$ & $29 \%$ & $17 \%$ & $54 \%$ \\
\hline Órgãos reguladores de outros países. & $38 \%$ & $38 \%$ & $25 \%$ & $40 \%$ & $4 \%$ & $46 \%$ \\
\hline Órgão fiscal de seu país. & $25 \%$ & $58 \%$ & $17 \%$ & $33 \%$ & $21 \%$ & $46 \%$ \\
\hline Legislação societária. & $13 \%$ & $79 \%$ & $8 \%$ & $33 \%$ & $17 \%$ & $50 \%$ \\
\hline Acionistas controladores. & $46 \%$ & $21 \%$ & $33 \%$ & $38 \%$ & $13 \%$ & $50 \%$ \\
\hline Gestores. & $25 \%$ & $33 \%$ & $42 \%$ & $8 \%$ & $79 \%$ & $8 \%$ \\
\hline
\end{tabular}


Com base nos dados da Tabela $9 \mathbf{0}$, podem-se destacar os seguintes resultados:

- Para a Contabilidade Financeira, percebe-se que os agentes, acionistas controladores, outras empresas do mercado, órgãos reguladores de outros países, gestores e órgãos de classe exercem pouca influência sobre a elaboração de relatórios financeiros. $\mathrm{O}$ resultado confirma o que havia sido identificado na Tabela 8. Por outro lado, também confirmando os resultados obtidos na Tabela 8, os agentes que influenciam ou regulam os relatórios financeiros são os órgãos governamentais, o FASB local e a legislação societária. Os órgãos fiscais de seu país também exercem alguma influência. Portanto, confirma-se que são os órgãos normativos que determinam as práticas de Contabilidade Financeira.

- Para a Contabilidade Gerencial, têm-se também resultados similares aos obtidos na Tabela 8. Assim, são os gestores, principalmente, e outras empresas do mercado que influenciam a elaboração de relatórios gerenciais.

\subsection{Bloco 9}

Responsável técnico pela elaboração

Esse Bloco também apresenta dois objetivos. O primeiro é identificar, segundo a opinião dos respondentes, se o responsável pela elaboração dos relatórios financeiros e/ou relatórios gerenciais necessita ser registrado em órgão profissional de classe (no caso brasileiro, esse órgão é o Conselho Federal de Contabilidade). O segundo objetivo é aferir, na opinião dos respondentes, se o responsável pela elaboração dos relatórios financeiros e/ou gerenciais tem que ser necessariamente formado em Contabilidade, ou seja, se tem que ser um Contador.

Percebe-se que $8 \%$ dos respondentes consideram ser obrigatória a necessidade de registro por parte do profissional responsável tanto pelos relatórios financeiros quanto pelos relatórios gerenciais. Vide Tabela $10 \boldsymbol{0}$. Note-se, ainda, que, para $58 \%$ dos respondentes, é obrigatória a necessidade de registro em órgão profissional de classe por parte do responsável pela elaboração apenas dos relatórios financeiros. Nenhum dos respondentes entende que essa mesma obrigatoriedade seja válida apenas para os relatórios gerenciais. 34\% dos respondentes consideram que nem para os relatórios financeiros nem para os relatórios gerenciais essa obrigatoriedade seja válida.

Percebe-se que $8 \%$ dos respondentes consideram que o responsável tem que ser graduado em Contabilidade para a elaboração tanto dos relatórios financeiros quanto gerenciais. Vide Tabela $11 \bullet$. Metade dos respondentes considera que essa exigência é válida apenas para os relatórios financeiros, enquanto nenhum respondente con-

Tabela 9 Agentes que influenciam ou regulam os relatórios financeiros e gerenciais

\begin{tabular}{l|c|c|c|c|c|c}
\multirow{2}{*}{\multicolumn{1}{c|}{ Descrição }} & \multicolumn{3}{c|}{ Contabilidade Financeira } & \multicolumn{3}{c}{ Contabilidade Gerencial } \\
\cline { 2 - 7 } & Não & Sim & Não Respondeu & Não & Sim & Não Respondeu \\
\hline Outras empresas do mercado. & $21 \%$ & $13 \%$ & $67 \%$ & $8 \%$ & $33 \%$ & $58 \%$ \\
\hline Orgãos de classe. & $17 \%$ & $25 \%$ & $58 \%$ & $25 \%$ & $21 \%$ & $54 \%$ \\
\hline O FASB local. & $4 \%$ & $67 \%$ & $29 \%$ & $29 \%$ & $17 \%$ & $54 \%$ \\
\hline $\begin{array}{l}\text { Órgãos governamentais (federal, } \\
\text { estadual ou municipal). }\end{array}$ & $4 \%$ & $71 \%$ & $25 \%$ & $25 \%$ & $8 \%$ & $67 \%$ \\
\hline Órgãos reguladores de outros países. & $21 \%$ & $33 \%$ & $46 \%$ & $33 \%$ & $4 \%$ & $58 \%$ \\
\hline Órgão fiscal de seu país. & $13 \%$ & $50 \%$ & $38 \%$ & $25 \%$ & $8 \%$ & $67 \%$ \\
\hline Legislação societária. & $8 \%$ & $67 \%$ & $25 \%$ & $33 \%$ & $4 \%$ & $63 \%$ \\
\hline Acionistas controladores. & $25 \%$ & $17 \%$ & $58 \%$ & $25 \%$ & $17 \%$ & $58 \%$ \\
\hline Gestores. & $17 \%$ & $25 \%$ & $58 \%$ & $4 \%$ & $58 \%$ & $38 \%$ \\
\hline
\end{tabular}

Tabela 10 | Registro em órgão profissional de classe

\begin{tabular}{l|c|l}
\multicolumn{1}{c|}{ Resposta } & $\%$ & \multicolumn{1}{c}{ Países } \\
$\begin{array}{l}\text { Sim, para a elaboração das demonstrações da Contabilidade } \\
\text { Financeira e Contabilidade Gerencial. }\end{array}$ & $8 \%$ & Índia e Tunísia. \\
\hline $\begin{array}{l}\text { Sim, para elaboração das demonstrações da Contabilidade } \\
\text { Financeira. }\end{array}$ & $58 \%$ & $\begin{array}{l}\text { Suécia, Brasil, Portugal, Noruega, Canadá, Alemanha, } \\
\text { Grécia, África do Sul, Espanha, Argentina, Colômbia, } \\
\text { China, Japão e Grã-Bretanha. }\end{array}$ \\
\hline $\begin{array}{l}\text { Sim, para elaboração das demonstrações da Contabilidade } \\
\text { Gerencial. }\end{array}$ & 0 & $\begin{array}{l}\text { Polônia, México, Itália, EUA, Finlândia, Holanda, Taiwan } \\
\text { e Uruguai. }\end{array}$ \\
\hline Não, nenhum credenciamento é exigido em ambos os casos. & $34 \%$ & \\
\hline Não Respondeu. & 0 & -
\end{tabular}




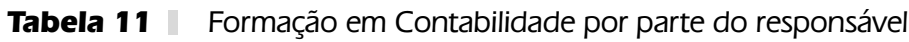

\begin{tabular}{|c|c|c|}
\hline Resposta & $\%$ & Países \\
\hline $\begin{array}{l}\text { Sim, para a elaboração das demonstrações da Contabilidade } \\
\text { Financeira e Contabilidade Gerencial. }\end{array}$ & $8 \%$ & Índia e Colômbia. \\
\hline $\begin{array}{l}\text { Sim, para elaboração das demonstrações da Contabilidade } \\
\text { Financeira. }\end{array}$ & $50 \%$ & $\begin{array}{l}\text { Suécia, Brasil, Noruega, México, Canadá, } \\
\text { Alemanha, Grécia, África do Sul, Argentina, } \\
\text { China, Japão e Taiwan. }\end{array}$ \\
\hline $\begin{array}{l}\text { Sim, para elaboração das demonstrações da Contabilidade } \\
\text { Gerencial. }\end{array}$ & 0 & ( \\
\hline Não, nenhum credenciamento é exigido. & $29 \%$ & $\begin{array}{l}\text { Portugal, Polônia, Itália, EUA, Finlândia, } \\
\text { Holanda e Grã-Bretanha. }\end{array}$ \\
\hline Não Respondeu. & $13 \%$ & Tunísia, Espanha e Uruguai. \\
\hline
\end{tabular}

sidera válida essa exigência para os relatórios gerenciais. Para 29\% dos respondentes, a exigência de formação em Contabilidade para o responsável não é válida para qualquer das Contabilidades.

Pode-se concluir que existe uma tendência para a Contabilidade Financeira de que o responsável tenha que ser tanto registrado em órgão profissional de classe quanto ser graduado em Contabilidade. Para a Contabilidade Gerencial essa tendência não se confirma, podendo ser o responsável pela elaboração dos relatórios gerenciais um profissional sem qualquer vínculo com o órgão profissional de classe e sem formação específica em Contabilidade.

\subsection{Bloco 10 Área de atuação}

O último Bloco procurou caracterizar os respondentes em termos de atuação nas duas Contabilidades:

- $8 \%$ atuam apenas com Contabilidade Financeira;

- $63 \%$ atuam apenas com Contabilidade Gerencial;

- $29 \%$ atuam nas Contabilidades Financeira e Gerencial.

Como se percebe, a absoluta maioria dos respondentes se apresenta como atuando na Contabilidade Gerencial e em ambas as Contabilidades.

\section{COMENTÁRIOS FINAIS}

Esta pesquisa demonstrou que existem, conforme previsto na revisão da literatura, elementos que distanciam as duas Contabilidades. Entretanto, tais distanciamentos não são homogêneos tanto no que se referem aos elementos quanto aos países, sendo percebidas diferenciações com variados graus de intensidade. A conhecida indução normativa da Contabilidade Financeira apresenta-se de maneira distinta em vários países e a flexibilidade de adoção de elementos por parte da Contabilidade Gerencial também tem peculiaridades quando observada em termos de conjunto de países. Provavelmente tais diversidades decorrem de diferentes estágios e graus de complexidade vivenciados.

Os resultados obtidos confirmam a necessidade de que as informações destinadas para os usuários internos não possam ser as mesmas e seguindo os mesmos padrões que as informações voltadas para os usuários externos. A maioria dos respondentes considerou a necessidade de existir duas Contabilidades e que a base de dados monetários utilizada pela Contabilidade Gerencial, além de poder ser diferente, pode mesmo não ser necessariamente consistente com a da Contabilidade Financeira e incluir dados não-monetários.

As principais diferenças percebidas nos elementos analisados são as seguintes:

- Quanto à aplicação dos princípios, a maioria dos respondentes considerou que o custo histórico como base de valor, a realização da receita e a prudência não podem produzir os mesmos valores na Contabilidade Financeira e na Contabilidade Gerencial. Em outras palavras, a Contabilidade Gerencial pode produzir números utilizando outro critério de avaliação de ativos, sendo menos conservadora em seus cálculos.

- No que se refere ao foco de análise, os respondentes consideraram que, para a Contabilidade Financeira, a ênfase recai na empresa como um todo. $\mathrm{Na}$ Contabilidade Gerencial, por sua vez, a ênfase, embora também inclua a empresa como um todo, recai fortemente nas análises por unidades de negócios, centro de custos, grupo de produtos e por projetos. Por fim, os respondentes consideraram que aspectos comportamentais podem afetar a Contabilidade Gerencial, enquanto, na Contabilidade Financeira, isso é pouco provável.

- A freqüência de divulgação de relatórios na Contabilidade Financeira, na opinião dos respondentes, é basicamente anual, enquanto, na Contabilidade Gerencial, publicações mensais são demandadas.

- Quanto ao grau de confiabilidade, os respondentes consideraram que os relatórios financeiros necessitam de auditoria externa, não havendo essa exigência para os relatórios gerenciais. 
- No que se refere aos agentes que poderiam influenciar e regular e aos que efetivamente influenciam e regulam, percebeu-se que, na opinião dos respondentes, a Contabilidade Financeira sofre controle principalmente normativo (FASB local, órgãos governamentais e legislação societária), enquanto a Contabilidade Gerencial pode ser, e é de fato, influenciada pelo estilo de seus gestores e por outras empresas do mercado.

- Por fim, o responsável técnico pelos relatórios financeiros necessita, segundo os respondentes, tanto ser registrado em órgão profissional de classe, quanto ser graduado em Contabilidade. Essas exigências não se aplicariam ao responsável técnico pelos relatórios gerenciais.
Em relação aos resultados obtidos, é preciso considerar que a maior parte dos respondentes atua com Contabilidade Gerencial, o que pode trazer viés. Além disso, é preciso destacar que, em algumas questões, o índice de não respondentes foi relativamente alto. De qualquer forma, este estudo traz importante contribuição ao tema ao buscar uma visão de respondentes de diversos países.

Futuras pesquisas podem aprofundar este estudo, buscando caracterizar o entendimento de Contabilidade Financeira e Contabilidade Gerencial nos diversos países. Além disso, pode-se procurar agrupar países que possuam entendimentos similares. Embora não sejam tarefas simples, podem contribuir para um consenso em relação às causas das diferenças existentes entre Contabilidade Financeira e Contabilidade Gerencial.

\title{
Referências Bibliográficas
}

Anderson, Henry R.; Needles, Belverd E.; Caldwell, James C.. Managerial Accounting. Boston: Houghton, 1989.

Anthony, R.N.; Welsch, G.. Fundamentals of management accounting. 13th edition, Homewood: Irwin, 1981.

Comissão de Valores Mobiliários - CVM. Deliberação CVM n. 29/86. Estrutura conceitual básica da contabilidade. 1986.

Financial Accounting Standards Board - FASB. Statements Financial Accounting Concepts n. 2. FASB, 1980.

Hansen, D. R.; Mowen, Maryanne M.. Cost management. $2^{\text {nd }}$. edition, Cincinnati, Ohio: South-Western College Publications, 1997.

Horngren, C.T.; Foster, G.; Datar S. M.. Cost accounting. São Paulo: Prentice-Hall: 2000.

Horngren; Sundem; Stratton. Contabilidade gerencial. 12ª edição. São Paulo: Prentice-Hall, 2004.

Institute Accounting Standards Board - IASB. Framework for the preparation and presentation of financial statements. IASC, 1989.

KAPLAN, R. S.; ATKINSON, A. A.. Advanced management accounting. 2 ed. New Jersey: Prentice-Hall, 1989.

Louderback, J.G.; Holmen, J.; Dominiak, G.. Managerial accounting. 9th edition, Cincinnati: South-Western College Publ, 2000.

Richardson, A.J.. Professional dominance: the relationship between financial accounting and managerial accounting, 1926-1986. Accounting Historians Journal, vol.29, 2, p.91-121, Dec.2002.

\section{NOTA - Endereço dos autores}

\author{
Universidade de São Paulo \\ Faculdade de Economia, Administração e Contabilidade \\ Departamento de Contabilidade e Atuária \\ Av. Prof. Luciano Gualberto, 908 - prédio 3 - cidade universitária \\ São Paulo - SP \\ 05508-900
}

